\title{
Influência da severidade de mancha angular na eficiência fotossintética da área foliar sadia de feijoeiro, sob condições de campo
}

\section{Photosynthetic efficiency of healthy leaf area influenced by angular leaf spot severity in bean field}

\author{
Marcelo Giovanetti Canteri ${ }^{1 *}$; Cláudia Vieira Godoy²
}

\begin{abstract}
Resumo
O objetivo do trabalho foi demonstrar, em parcelas experimentais sob condições de campo, a relação entre área foliar sadia, severidade de mancha angular e produção em feijoeiro indicando a influência desta relação na eficiência fotossintética do tecido foliar remanescentes nas plantas. Área foliar e severidade de mancha angular [Phaeoisariopsis griseola (Sacc.) Ferraris] de feijoeiro foram avaliadas semanalmente, iniciando-se aos 30 dias após a emergência (DAE). Obtiveram-se diferentes níveis de severidade variando-se a data de início de aplicação da mistura fungicida (fentin hydroxide $0,10 \%+$ tebuconazole $0,04 \%$ ). Variações na quantidade de área foliar foram obtidas em função da variação inerente entre plantas e das diferenças de condições físicoquímicas encontradas no solo das parcelas. A relação entre duração de área foliar sadia $(H A D)$ e a área sob a curva de progresso da doença $(A U D P C)$ e a produção $\left(\mathrm{g} \mathrm{m}^{-2}\right)$ apresentou $\mathrm{R}^{2}=74,8 \%$ e entre e absorção da área foliar sadia (HAA), $A U D P C$ e a produção $\left(\mathrm{g} \mathrm{m}^{-2}\right)$ apresentou $\mathrm{R}^{2}=74,7 \%$. Os resultados indicaram que houve redução na produção em parcelas com valores altos de $A U D P C$, mesmo naquelas com mesmo nível de área foliar sadia (HAD), ou seja, a doença influenciou a eficiência fotossintética da área foliar sadia das plantas, além de impedir que a área doente necrosada produzisse.

Palavras-chave: Fitopatometria, Phaeoisariopsis griseola, Phaseolus vulgaris
\end{abstract}

\begin{abstract}
This paper aimed to show the relationship among healthy leaf area, angular leaf spot severity and bean yield, under field conditions, indicating the influence of this relationship on photosynthetic efficiency of leaf tissue remaining on plants. Leaf area and severity of angular leaf spot [Phaeoisariopsis griseola (Sacc.) Ferraris] of bean were weekly assessed, beginning at 30 days after emergence (DAE). Different levels of severity were reached varying the timing of fungicide spraying (fentin hydroxide $0.10 \%+$ tebuconazole $0.04 \%$ ). Variations on total leaf area were consequence of natural variation on plants and also due to different physic and chemical soil conditions among plots. The relation between healthy leaf area duration $(H A D)$ and area under disease progress curve $(A U D P C)$ and yield $\left(\mathrm{g} \mathrm{m}^{-2}\right)$ presented $\mathrm{R}^{2}=74.8 \%$ and healthy area absorption (HAA), $A U D P C$ and yield $\left(\mathrm{g} \mathrm{m}^{-2}\right)$ presented $\mathrm{R}^{2}=74.7 \%$. Results indicated reduction of yield when severity (AUDPC) was high, even in plots with same level of healthy leaf area. So, the disease influenced the photosynthetic efficiency of healthy leaf area, besides avoiding the production of the necrotic tissue.
\end{abstract}

Key words: Phytopatometry, Phaeoisariopsis griseola, Phaseolus vulgaris

\footnotetext{
${ }^{1}$ Professor Dr., Departamento de Agronomia, CCA, UEL, C.P.6001, CEP 86051-990, Londrina, PR, Tel. (43)3371-4555, E-mail:canteri@uel.br

2 Pesquisadora Dra, Embrapa Soja, Caixa Postal 231, CEP 86001-970, Londrina, PR, fax (43)3371-6100, E-mail:godoy@cnpso.embrapa.br.

* Autor para correspondência.
} 


\section{Introdução}

A mancha angular do feijoeiro, causada pelo fungo Phaeoisariopsis griseola (Sacc.) Ferraris, ocorre na maioria das regiões produtoras no Brasil. Reduções de produtividade de até $45 \%$ têm sido relatadas para diferentes variedades (SARTORATO; RAVA, 1992). No Estado do Paraná, esta doença vem se tornando cada vez mais importante, principalmente em regiões onde se realiza o cultivo sucessivo de materiais suscetíveis. Além da necrose do tecido foliar, a queda de folhas é uma das principais causas, atribuída à mancha angular, da redução na produção, uma vez que resulta na diminuição de área foliar fotossinteticamente ativa (CANTERI; DALLA PRIA; SILVA, 1999).

A tentativa do estabelecimento de equação de dano relacionando severidade da doença com redução de produção, tem mostrado que funções deste tipo, obtidas para algumas cultivares nem sempre podem ser empregadas para outras cultivares (BERGAMIN FILHO, et al., 1997) e muitas vezes, essas relações não podem ser determinadas (CARNEIRO; AMORIM; BERGAMIN FILHO, 1997). A ausência de relação quantitativa tem sido relatada por diferentes autores (WAGGONER; BERGER, 1987; LOPES; BERGER; BERGAMIN FILHO, 1994; BERGAMIN FILHO, 1997), os quais postulam ser a produção vegetal função da duração da área foliar sadia e não da área foliar destruída pelo patógeno.

A produtividade de plantas doentes tem sido parcialmente explicada pela área foliar verde sadia e por variáveis correlatas, como: a duração da área foliar sadia (integral da área foliar sadia no tempo HAA) e a absorção da área foliar sadia (integral da radiação absorvida pelas folhas no tempo - HAD) (AMORIM et al., 1995; BERGAMIN FILHO et al., 1995; BERGAMIN FILHO et al., 1997; CARNEIRO; AMORIM; BERGAMIN FILHO, 1997; GODOY, 1995; SILVA, 1997). Os coeficientes de determinação obtidos pela regressão linear entre a produção e duração da área foliar sadia variam de
0,30 a 0,78 (BERGAMIN FILHO et al., 1997; CARNEIRO; AMORIM; BERGAMIN FILHO, 1997). Parte da variabilidade dos resultados pode ser decorrente do efeito negativo dos patógenos no tecido verde remanescente das folhas, o qual interfere no uso da radiação, e é ignorado no cálculo da área foliar sadia.

Para as doenças que interferem no uso da radiação, a proposta de Bastiaans (1991) pode ser utilizada, uma vez que permite classificar os patógenos de acordo com sua habilidade para afetar a eficiência de conversão de seus hospedeiros. $\mathrm{O}$ autor propõe uma relação entre lesão visual (proporção de área foliar visualmente doente) e lesão virtual (proporção de área foliar imaginária, igual ou superior à visual, dependendo do efeito do patógeno na taxa de eficiência de conversão). Assim, conforme sugerido por Johnson (1987), a produtividade de uma cultura é função da interceptação da radiação solar $\left(\mathrm{MJ} \mathrm{m}^{-2}\right)$ pela parte aérea da cultura e da eficiência do uso da radiação $\left(\mathrm{g} \mathrm{MJ}^{-1}\right)$.

Para mancha angular em feijoeiro, Bassanezi, Amorim e Bergamin Filho (2001) trabalhando com a cultivar Carioca em condições controladas com um analisador de $\mathrm{CO}_{2}$ infravermelho, determinaram que o conteúdo total de clorofila e a assimilação líquida de $\mathrm{CO}_{2}$ reduz proporcionalmente mais que a severidade da doença.

O objetivo do presente trabalho foi avaliar em parcelas experimentais sob condições de campo, a relação entre área foliar sadia, severidade de mancha angular e produção em feijoeiro, como indicador da influência desta relação na eficiência fotossintética do tecido foliar remanescente nas plantas.

\section{Material e Métodos}

O experimento foi conduzido em área pertencente ao Campo Demonstrativo e Experimental da Cooperativa Agropecuária Castrolanda Ltda., em Castro-PR, região apresenta predominância do tipo climático $\mathrm{Cfb}$. A época de semeadura foi determinada 
de acordo com a época de ocorrência de maiores epidemias de mancha angular, observada em cultivos anteriores. A cultivar Carioca foi semeada em 14/ 01/97, sob sistema de plantio direto, em palhada de trigo, em solo classificado como Latossolo Bruno distrófico, de textura argilosa. A emergência das plântulas ocorreu em 21/01/97 e as parcelas foram compostas por 6 linhas com 5,00 m e espaçadas de 0,40 m entre si com 12 plantas por metro linear, após desbaste. Foram avaliados no ensaio nove tratamentos, com quatro repetições, totalizando 36 parcelas. Os fungicidas foram aplicados em uma ou mais vezes, em diferentes épocas buscando obter parcelas com diferentes níveis de severidade da doença. Foram mantidos dois tratamentos sem aplicação de fungicidas (tratamentos 08 e 09), localizados em áreas com diferentes níveis de fertilidade. No tratamento 03 o cartap (500 g i.a./ha) foi aplicado aos 30, 42, 55 e 69 dias após a emergência (DAE), visando controlar a ferrugem, em função da especificidade deste produto para a doença. A mistura dos fungicidas fentin hydroxide $(0,10 \%)+$ tebuconazole $(0,04 \%)$ foi utilizada para controle da mancha angular. No tratamento 01, considerado "parcela controle" (LOPES; BERGER; BERGAMIN FILHO, 1994), a aplicação foi aos 30, 42, 55 e 69 DAE, buscando manter as plantas livres da mancha angular. No tratamento 02 a aplicação da mistura dos fungicidas foi aos 30 e 42 DAE, o tratamento 04 aos 42,55 e 69 DAE, o tratamento 05 aos 48 e 62 DAE, o tratamento 06 aos 55 e 69 DAE e no tratamento 07 aos 62 DAE.

Semanalmente foram avaliados o crescimento de plantas, a severidade de mancha angular e produtividade, nas quatro linhas centrais de cada parcela, mantendo-se uma bordadura de $0,50 \mathrm{~m}$ ao final de cada linha, tendo sido avaliadas seis plantas por parcela, previamente marcadas com fita plástica, totalizando 216 plantas para todo o ensaio.

A área foliar $\left(L A, \mathrm{~cm}^{2}\right)$ de todas as folhas das plantas marcadas foi estimada aos 30, 39, 44, 51, 58, 64, 72 e 79 DAE, através de mensuração da largura máxima do folíolo na parte central de cada folha $(L$, $\mathrm{cm}$ ) e emprego da equação $L A=2,1 \times L^{2}$ (SCHULD, 1996).

A severidade de mancha angular foi avaliada empregando-se escala diagramática de GODOY et al. (1995). Simultaneamente às avaliações da área foliar foi estimada a severidade média em percentuais, para os três folíolos, em todas as folhas das plantas marcadas. Em cada avaliação foi determinado o estádio de crescimento de acordo com uma escala descritiva apresentada por Schoonhoven e PastorCorrales (1987): V0 = germinação; V1 = emergência; V2 = abertura de folhas primárias; V3 = primeira folha trifoliolada; V4 = terceira folha trifoliolada; R5 = pré-floração; R6 = floração; R7 = formação de vagens; $R 8$ = enchimento de vagens; $R$ 9 = maturação fisiológica.

A colheita foi realizada aos 85 dias da emergência, sendo que para a produção foram colhidas as quatro linhas centrais de cada parcela, em uma área de 6,40 $\mathrm{m}^{2}$, determinando-se a umidade dos grãos e os resultados padronizados para $13 \%$ de umidade. Para estimativa da densidade de plantas por metro quadrado determinou-se o número de plantas na área útil da parcela no momento da colheita. Optou-se por trabalhar com a produção da parcela (método da parcela experimental) ao invés da produção por planta (método da planta individual), para que fosse possível estabelecer relações desta variável com medidas de eficiência fotossintética (BERGAMIN FILHO; AMORIM, 1996).

$\mathrm{O}$ valor da área sob a curva de progresso da doença $(A U D P C)$ para cada parcela foi calculado por integração trapezoidal:

$$
A U D P C=\sum_{i=1}^{n-1}\left[\left(X_{i}+X_{i+1}\right) / 2\right]\left(t_{i+1}-t_{i}\right) ;
$$

onde $X$ é a severidade média da doença por parcela (porcentagem), $X_{i}=X\left(t_{i}\right), n$ é o número de avaliações e $\left(t_{i+1}-t_{i}\right)$ é o intervalo entre duas avaliações consecutivas. 
Os valores de índice de área foliar $(L A I)$ de cada parcela foram obtidos pela multiplicação da área foliar média por planta $\left(\mathrm{m}^{2}\right)$ pela densidade de plantas por $\mathrm{m}^{2}$ observada no dia da colheita. A duração de área foliar sadia $(H A D)$ para cada parcela foi calculada pela fórmula $H A D=\sum_{i=1}^{n-1}\left\{\left[L A I_{i}\left(1-X_{i}\right)+L A I_{i+1}\left(1-X_{i+1}\right)\right] / 2\right\}\left(t_{i+1}-t_{i}\right) ;$ onde $L A I_{i}=\operatorname{LAI}\left(t_{i}\right)$. $\mathrm{O}$ valor do índice de área foliar sadio (HLAI) para cada data de avaliação foi calculado como $H L A I=\operatorname{LAI}(1-X)$.

Os valores de radiação interceptada $\left(R I_{i}\right)$ em MJ $\mathrm{m}^{-2}$ foram calculados como: $R I_{i}=I_{i}\left[1-\exp \left(-k L A I_{i}\right)\right]$ ; em que $I_{i}$ é a média de radiação solar incidente (MJ $\left.\mathrm{m}^{-2}\right)$ no período $\left(t_{i+1}-t_{i}\right)$ e $k$ é o coeficiente de extinção; usou-se $k=0,7$ (BERGAMIN FILHO et al., 1997).

$\mathrm{O}$ valor da absorção de área foliar sadia $(H A A) \mathrm{em}$ $\mathrm{MJ} \mathrm{m}^{-2}$ para cada parcela foi calculado como $H A A=$ $\sum_{i=1}^{n-1} I_{i}\left(\left\{\left(1-X_{i}\right)\left[1-\exp \left(-k L A I_{i}\right)\right]+\left(1-X_{i+1}\right)\left[1-\exp \left(-k L A I_{i+1}\right)\right]\right\} / 2\right)\left(t_{i+1}-t_{i}\right)$

Os valores da radiação interceptada pela área foliar sadia $\left(H R I, \mathrm{MJ} \mathrm{m}^{-2}\right)$, para cada data de avaliação, foram calculados pela fórmula $H R I=R I$ $(1-X)$. A radiação solar incidente $(I)$ foi medida por uma estação meteorológica computadorizada situada ao lado da área experimental.
Calculou-se a eficiência do uso da radiação ( $R U E$, em $\mathrm{g} \mathrm{MJ}^{-1}$ ) para cada parcela pela divisão da produção $\left(\mathrm{g} \mathrm{m}^{-2}\right)$ pela $H A A\left(\mathrm{MJ} \mathrm{m}^{-2}\right)$.

A eficiência dos tratamentos foi examinada por análise de variância usando-se o programa PlotIT for Windows (Scientific Programming Enterprises, Haslett, MI). As relações entre produtividade, $H A D$, HAA, HLAI, HRI, medidas de refletância e severidade da doença foram examinadas pelos métodos de regressão linear e não-linear usando-se o programa STATISTICA (StatSoft, Tulsa, OK). Para a análise dos resultados de HLAI, HRI e refletância foram consideradas as 36 parcelas isoladamente.

\section{Resultados e Discussão}

Para mancha angular, doença predominante, os primeiros sintomas foram observados aos 30 dias DAE, enquanto que para ferrugem e antracnose a severidade foi desprezível. A epidemia da mancha angular não foi severa, com $A U D P C$ de 52,5 para o nível máximo de severidade nas avaliações de toda a planta, até o estádio R8 quando o nível foi $6,05 \%$. Embora não tenha sido constatada diferença significativa entre os tratamentos com e sem fungicidas foi observada maior produtividade nas parcelas com os tratamentos com fungicidas (Tabela 1).

Tabela 1. Absorção de área foliar sadia (HAA), área sob a curva de progresso de mancha angular (AUDPC), eficiência fotossintética $(R U E)$ para produção de grãos e produtividade de plantas de feijoeiro cv. Carioca pulverizadas com fungicidas em diferentes dias após a emergência (DAE).

\begin{tabular}{|c|c|c|c|c|c|}
\hline & & $\begin{array}{c}\text { Área foliar } \\
H A A\left(\mathrm{MJ} \mathrm{m}^{-2}\right)\end{array}$ & $\begin{array}{l}\text { Doença } \\
A U D P C\end{array}$ & $\begin{array}{c}R U E \\
\mathrm{~g} \mathrm{MJ}^{-1}\end{array}$ & $\begin{array}{l}\text { Produtividade } \\
\qquad\left(\mathrm{g} \mathrm{m}^{-2}\right)\end{array}$ \\
\hline & aplicação(DAE) & média $\pm \quad \mathrm{SE}^{* *}$ & média $\pm \mathrm{SE}$ & média \pm & média \pm SE \\
\hline 01 & $30-42-55-69$ & $614,2 \pm 19,8 \mathrm{a}$ & $12,0 \pm 1,3 \mathrm{a}$ & $0,46 \pm 0,010 \mathrm{a}$ & $282,9 \pm 2,2 \mathrm{ab}$ \\
\hline 02 & $30-42$ & $628,3 \pm 29,0 \mathrm{a}$ & $12,8 \pm 1,7 \mathrm{a}$ & $0,46 \pm 0,010 \mathrm{a}$ & $288,9 \pm 12,7 \mathrm{ab}$ \\
\hline 03 & $30-42-55-69$ & $595,1 \pm 17,5 \mathrm{a}$ & $37,0 \pm 1,8 \quad \mathrm{c}$ & $0,45 \pm 0,010 \mathrm{~A}$ & $269,8 \pm 3,4 \mathrm{ab}$ \\
\hline 04 & $42-55-, 69$ & $622,8 \pm 26,9 \mathrm{a}$ & $20,1 \pm 2,6 \mathrm{ab}$ & $0,46 \pm 0,020 \mathrm{~A}$ & $284,5 \pm 4,8 \mathrm{ab}$ \\
\hline 05 & $48-62$ & $654,6 \pm 17,2 \mathrm{a}$ & $22,9 \pm 1,4 \mathrm{abc}$ & $0,46 \pm 0,010 \mathrm{~A}$ & $303,3 \pm 3,9 b$ \\
\hline 06 & $55-69$ & $614,0 \pm 20,8 \mathrm{a}$ & $27,8 \pm 4,7 a b c$ & $0,46 \pm 0,010 \mathrm{~A}$ & $282,9 \pm 5,1 \mathrm{ab}$ \\
\hline 07 & 62 & $619,6 \pm 15,1 \mathrm{a}$ & $37,4 \pm 6,6 \quad c$ & $0,41 \pm 0,010 \mathrm{~A}$ & $257,0 \pm 11,3 \mathrm{a}$ \\
\hline 08 & sem fungicida & $601,6 \pm 34,9 a$ & $38,2 \pm 4,4 \quad c$ & $0,45 \pm 0,020 \mathrm{~A}$ & $269,7 \pm 7,6 a b$ \\
\hline 09 & sem fungicida & $619,4 \pm 21,1 \mathrm{a}$ & $36,6 \pm 2,6 \mathrm{bc}$ & $0,44 \pm 0,001 \mathrm{~A}$ & $273,2 \pm 9,2 \mathrm{ab}$ \\
\hline
\end{tabular}

Médias seguidas de mesma letra não diferem estatisticamente entre si pelo teste de Tukey $(\mathrm{P}<0,05)$.

* As pulverizações foram realizadas com a mistura dos fungicidas fentin hydroxide $(0,10 \%)+$ tebuconazole $(0,04 \%)$, exceto o tratamento 03 onde foi pulverizado Cartap (500 g i.a./ha).

** $\mathrm{SE}=$ erro padrão da amostra. 
A possibilidade de redução da eficiência fotossintética provocada por P. griseola foi avaliada após ter sido observado que aquelas parcelas com valores semelhantes de $H A D$ e de $H A A$ (variáveis da área foliar sadia) apresentavam diferentes valores de produção, para os diferentes valores de $A U D P C$ (Tabela 1). Ao se colocar os valores destas variáveis em um mesmo gráfico foi observada correlação entre ambas (Figura 1). Para uma mesma duração de área foliar sadia $(H A D)$ ocorreu redução da produção em função da área sob a curva de progresso da doença, ou seja, a doença influenciou na produção da área foliar sadia remanescente nas plantas. Houve relação positiva entre produção, em $\mathrm{g} \mathrm{m}^{-2}, H A D$ e $A U D P C$ $\left(\mathrm{R}^{2}=74,8 \%\right)$, representada pela equação: produção $=$ 244,7 - 0,91 AUDPC + 0,42 HAD, indicando que para uma mesma $H A D$, a produção pode variar em função da $A U D P C$, ou seja a severidade da mancha angular, representada pela $A U D P C$, interfere na eficiência fotossintética da área foliar sadia. Resultados semelhantes foram obtidos quando se utilizou $H A A$ ao invés de $H A D\left(\mathrm{R}^{2}=74,7 \%\right)$, para a equação: produção $=134,5-0,78 A U D P C+0,27 H A A$.

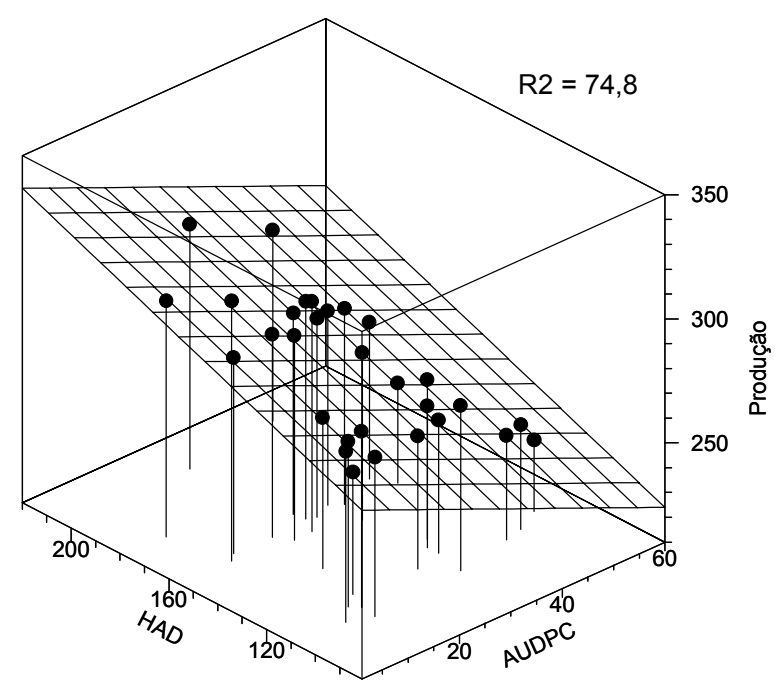

Figura 1. Relação entre duração de área foliar sadia $(H A D)$ com a área sob a curva de progresso da doença $(A U D P C)$ e produção $\left(\mathrm{g} \mathrm{m}^{-2}\right)$, em diferentes tratamentos com fungicidas, para controle de mancha angular em feijoeiro.

O efeito do patógeno na capacidade fotossintética do hospedeiro varia de acordo com o patossistema em consideração. Nas relações patógeno/hospedeiro hemibiotróficos, que produzem sintomas necróticos, a fotossíntese líquida é afetada primeiramente pela degeneração dos cloroplastos, a qual resulta em perda de clorofila e redução da fixação de $\mathrm{CO}_{2}$ (GOODMAN; KIRÁLY; WOOD, 1986). Bassanezi, Amorim e Bergamin Filho (2001) trabalhando com a cultivar de feijão Carioca, em condições controladas utilizando um analisador de $\mathrm{CO}_{2}$ infravermelho, observaram que os valores para conteúdo total de clorofila e para assimilação líquida de $\mathrm{CO}_{2}$ reduziram proporcionalmente mais do que a severidade da mancha angular. Esses autores concluíram que a ausência de diferença significativa $(p>0,05)$ entre assimilação líquida de $\mathrm{CO}_{2}$, baseada no conteúdo de clorofila entre folhas sadias e com mancha angular, indica que a eficiência da clorofila remanescente não é alterada naquelas folhas com mancha angular.

Para confirmar a interferência da mancha angular na eficiência fotossintética, calculou-se a eficiência do uso da radiação para produção de grãos $(R U E)$, em $\mathrm{g} \mathrm{MJ}^{-1}$, para os 9 tratamentos. A estimativa da $R U E$ foi obtida dividindo-se a produção $\left(\mathrm{g} \mathrm{m}^{-2}\right)$ pela $H A A\left(\mathrm{MJ} \mathrm{m}^{-2}\right)$ para cada tratamento (Tabela 1$)$, sendo a maior $R U E$ observada para o tratamento $1(0,46 \pm$ $\left.0,01 \mathrm{~g} \mathrm{MJ}^{-1}\right)$ e a menor $R U E$ para o tratamento 7 $\left(0,41 \pm 0,01 \mathrm{~g} \mathrm{MJ}^{-1}\right)$. Não foram observadas diferenças estatísticas significativas $(\mathrm{P}<0,05)$ entre os tratamentos. Os resultados foram consistentes, onde o tratamento com maior controle da doença apresentou a maior RUE. Esse resultado está de acordo com as observações de Bassanezi, Amorim e Bergamin Filho (2001), que realizaram medições diretas das taxas de fotossíntese de plantas sadias e doentes em feijoeiro. Alguns autores afirmam que somente avaliações diretas mostram se realmente há variação na RUE (VAN OIJEN, 1990).

Em condições de campo, Bergamin Filho et al. (1997) não observaram variações significativas da $R U E$ entre parcelas doentes e sadias, para ensaios com HLAI máximo próximo a 3, porém verificaram grande variação na $R U E$ para o ensaio com $H L A I$ máximo próximo a 5. No presente estudo, com $H L A I$ 
máximo próximo a 5 , não foi constatado variação significativa $(\mathrm{P}>0,05)$ para $R U E$, mas houve relação produção x $A U D P C \times$ x $H A A$ (Figura 2), o que indica variação na eficiência fotossintética. Os resultados demonstram a importância da mensuração da área foliar para correlacionar com os danos, e também com a quantidade de doença, para procurar conhecer qual foi a redução na eficiência fotossintética da área foliar remanescente na cultura.

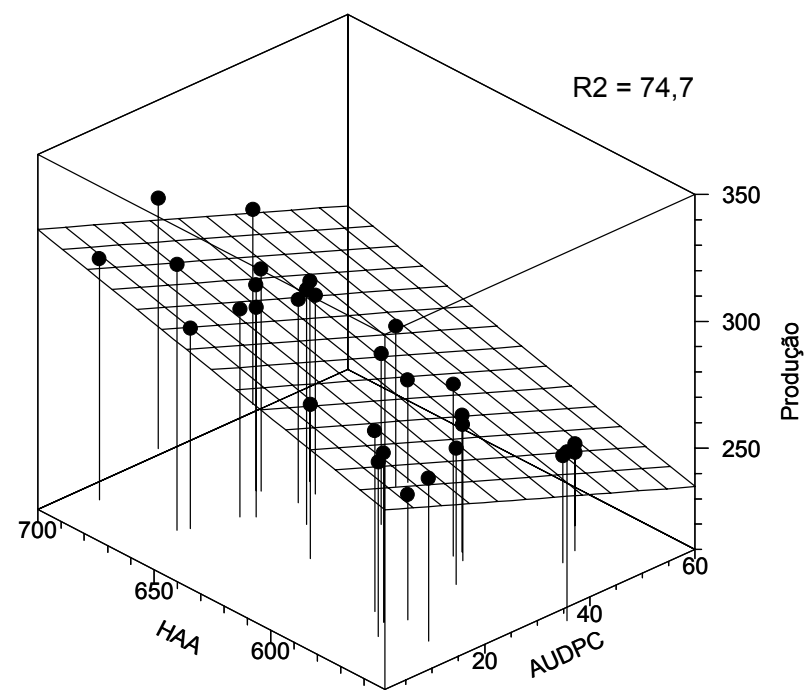

Figura 2. Relação entre absorção da área foliar sadia $(H A A)$ com área sob a curva de progresso da doença $(A U D P C) \mathrm{e}$ produção $\left(\mathrm{g} \mathrm{m}^{-2}\right)$, em diferentes tratamentos com fungicidas, para controle de mancha angular em feijoeiro.

\section{Conclusões}

Sob condições de campo houve correlação entre área foliar sadia, severidade de mancha angular $(P$. griseola) e produção de feijoeiro, indicando que há influência da quantidade de doença na eficiência fotossintética da área foliar sadia remanescente.

\section{Agradecimentos}

Ao Conselho Nacional de Pesquisa e Desenvolvimento Científico e Tecnológico (CNPq) pelo apoio financeiro.

\section{Referências}

AMORIM, L.; BERGAMIN FILHO, A.; GODOY, C. V.; IAMAUTI, M. T.; NUNES, W. M.; CARNEIRO, S. M. T. P. G. Avaliação de danos na cultura do feijoeiro. Summa Phytopathologica, Jaguariuna, v. 21, p. 82-84, 1995.

BASSANEZI. R. B.; AMORIM, L.; BERGAMIN FILHO, A. Eficiência fotossintética de folhas de feijoeiro infectadas com o vírus do mosaico-em-desenho, Uromyces appendiculatus e Phaeosphaeria griseola. Summa Phytopathologica, Jaguariuna, v. 27, p. 5-11, 2001.

BASTIAANS, L. Ratio between virtual and visual lesion size as a measure to describe reduction in leaf photosynthesis of rice due to leaf blast. Phytopathology, Saint Paul, v. 81, p. 611-615, 1991.

BERGAMINFILHO,A.; CARNEIRO, S.M.T.P.G.; GODOY, C. V.; AMORIM, L.; BERGER, R. D.; HAU, B. Angular leaf spot of Phaseolus beans: disease, crop growth, yield and management. Phytopathology, Saint Paul, v. 87, p. 506515, 1997.

BERGAMIN FILHO, A.; LOPES, D. B.; AMORIM, L.; GODOY, C. V.; BERGER, R. D. Avaliação de danos causados por doenças de plantas. Revisão Anual de Patologia de Plantas, Passo Fundo, v. 3, p. 133-184, 1995.

BERGAMIN FILHO, A.; AMORIM, L. Doenças de plantas tropicais: epidemiologia e controle econômico. São Paulo: Ceres, $1996.299 \mathrm{p}$.

CANTERI, M. G.; DALLA PRIA, M.; SILVA, O. C. Principais doenças fúngicas do feijoeiro: orientações para manejo econômico e ecológico. Ponta Grossa: UEPG, 1999. $178 \mathrm{p}$.

CARNEIRO, S. M. T. P. G.; AMORIM, L.; BERGAMIN FILHO, A. Avaliação de dano provocado pela mancha angular em feijoeiro: relação entre severidade, área foliar e componente de produção. Fitopatologia Brasileira, Brasília, v. 22, p. 427-431, 1997.

GODOY, C. V. Danos causados pela mancha angular em feijoeiro, no município de Piracicaba. 1995. 72 f. Dissertação (Mestrado)-Escola Superior de Agricultura "Luiz de Queiroz”, Universidade de São Paulo, Piracicaba, 1995.

GODOY, C. V.; CARNEIRO, S. M. T. P. G.; IUMAUTI, M. T.; DALLA PRIA, M.; AMORIM, L.; BERGER, R. D.; BERGAMIN, A. Diagrammatic scales for bean diseases: development and validation. Zeitschrift für Pflanzenkrankheiten und Pflanzenschutz, Hannover, v. 104, n. 4, p. 336-345, 1997.

GOODMAN, R. N.; KIRÁLY, Z.; WOOD, K. R. The biochemistry and physiology of plant disease. Columbia: University of Missouri Press, 1986. 433 p. 
JOHNSON, K. B. Defoliation, disease, and growth: a reply. Phytopathology, Saint Paul, v. 77, p. 1495-1497, 1987.

LOPES, D. B.; BERGER, R. D.; BERGAMIN FILHO, A. Absorção da área foliar sadia (HAA): uma nova abordagem para a quantificação de dano e para o manejo integrado de doença. Summa Phytopathologica, Jaguariuna, v. 20, p. 143-151, 1994.

SARTORATO, A.; RAVA, C. A. Influência da cultivar e do número de inoculações na severidade da mancha angular (Isariopsis griseola) e nas perdas na produção do feijoeiro comum (Phaseolus vulgaris). Fitopatologia Brasileira, Brasília, v. 17, p. 247-251, 1992.

SCHOONHOVEN, A. V.; PASTOR-CORRALES, M. A. Sistema Estándar para la Evaluación de Germoplasma de Frijol. Cali: CIAT, 1987. 56 p.
SCHULD, P. Auswirkung des Befalls durch drei Blattpathogenen (Uromyces appendiculatus, Phaeoisariopsis griseola, und Colletotrichum lindemuthianum) auf das Wachstum und den Ertrag von Phaseolus-Bohnen. 1996. 215 f. Thesis (Ph.D.)-Hannover Universität. Hannover, 1996.

SILVA, M. B. Área foliar verde para estimar danos causados por doenças do feijão comum. 1997. 100 f. Tese (Doutorado)-Universidade Federal de Viçosa. Viçosa, 1997.

VAN OIJEN, M. Photosynthesis is not impaired in healthy tissue of blighted potato plants. Netherlands Journal of Plant Pathology, Wageningen, v. 96, p. 55-63, 1990.

WAGGONER, P. E.; BERGER, R. D. Defoliation, disease, and growth. Phytopathology, Saint Paul, v. 77, p. 393-398, 1987. 